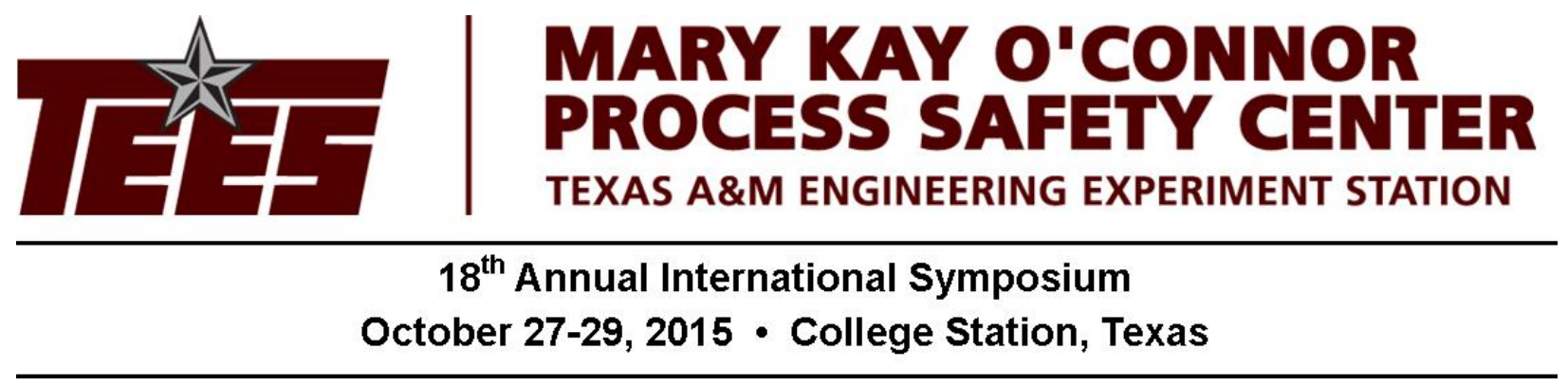

\title{
A Comprehensive Approach to API RP 752 and 753 Building Siting Studies
}

\author{
Jeffrey D. Marx and Benjamin R. Ishii \\ Quest Consultants Inc. \\ jdm@questconsult.com, bri@questconsult.com
}

\begin{abstract}
Facility siting studies are an important part of process safety, and are required for facilities that fall under OSHA's PSM program. Facility siting is frequently interpreted as performing a building siting study which adheres to the guidance given in API RP 752. Facility siting may also consider siting of temporary or portable buildings based on the guidance in API RP 753. While both API RP 752 and API RP 753 provide a framework and some guidance for performing building siting studies, they do not provide detailed methodologies or provide guidance on performing a detailed analysis. As a result many building siting studies are inconsistent in their overall approach, or in the way they address hazards. Due to the recent scrutiny applied to building siting studies, more attention has been given to provide evaluations which correctly describe the range of hazards that may affect an occupied building at a petrochemical facility. This paper outlines a comprehensive methodology for performing building siting studies at such facilities. The methodology addresses the applicable hazards and the available tools by which the potential impacts to building occupants can be evaluated.
\end{abstract}

\section{INTRODUCTION}

The American Petroleum Institute (API) has published two recommended practice (RP) documents, API RP 752 [1] and API RP 753 [2], which provide guidance for completing building siting studies. These documents provide the basic framework for an analysis, including a list of the hazards to consider and how to proceed through evaluation of potential building impacts towards providing mitigation measures. Traditionally, 752 and 753 studies have focused on explosion overpressure, primarily because it was believed that the hazards at many petrochemical facilities consisted mostly of vapor cloud explosions. However, a more balanced approach will include evaluation of all hazards, including flammable and/or toxic vapor infiltration, modeling of fire impacts, and enhanced treatment of overpressure. 
The purpose of API RP 752 and API RP 753 is to provide a framework and guidance for managing onsite risks to building occupants. Because of this, providing a comprehensive methodology that may be applied across a wide range of facilities is beyond the scope of the recommended practices. Because API RP 752 and 753 only provide guidance there are often misunderstandings and questions about how to apply them. The recommended practices may be applied to, but are not limited to, facilities covered by OSHA's process safety management program, 29 CFR 1910.119 [3]. Due to the wide range of facilities covered, questions about API RP 752 and 753 often arise concerning how to apply the guidance to a facility with unique process or layout features. This paper compliments API RP 752 and 753 by providing a comprehensive methodology for performing building siting studies in a consistent manner for the range of chemical and petrochemical facilities to which they are applied.

While a basic consequence analysis is the starting point for any 752 analysis, many studies quickly find that the impacts to buildings are greater than what would be defined as clearly acceptable. Thus, the building siting study must expand its scope to include evaluation beyond a consequence-only approach. This could include some of the following options:

- Implementation of mitigation measures

- Qualitative risk evaluation

- Event probability assessment

- Fire evacuation, escalation, or dosage analysis

- Pressure-impulse (P-I) curves, structural analysis

- Infiltration analysis

If the above options are not sufficient to qualitatively demonstrate an acceptably low level of risk at a building, there are several quantitative risk-based methodologies that could be considered:

- Overpressure exceedance

- Probability of building damage

- Full quantitative risk analysis (QRA)

- F-N for occupants

The challenge in building siting is applying detailed or risk-based analyses in a manner such that building occupant protection is handled consistently for all hazards and for different facilities. The sections below outline the required and optional parts of a 752 and 753 analysis and present a comprehensive methodology for implementing building siting in a consistent manner for a range of chemical and petrochemical facilities.

\section{HAZARDS IDENTIFICATION AND DEFINITION}

API RP 752 and API RP 753 introduce three classes of hazards to be evaluated:

- Explosion overpressure

- Fire radiation

- Toxic gas exposure 
Traditional building siting studies have for years focused on the overpressure (or blast wave) hazard associated with vapor cloud explosions. Analyses often took the form of overpressure prediction at occupied buildings, with little detailed analysis of other hazards. Fire radiation was sometimes addressed with spacing tables or simple rules. In recent years, more attention has been given to other hazards which may be capable of affecting occupants of buildings. Clearly, most buildings will provide occupant protection in the event of an external flash fire, but the evaluation of flammable gas infiltration has not been extensively applied. Likewise, where toxic gases are present at the facility, dispersion analyses may have evaluated outdoor toxic gas levels, but the additional check for infiltration was often ignored. In addition, most buildings do provide shielding against thermal radiation, but an analysis of occupant vulnerability and the potential for escape may have not been performed.

In the comprehensive building siting study, the list of specific hazards is defined as:

- Exposure to a blast wave following an explosion which may affect building occupants

- Exposure to fire radiation (jet fires, pool fires, and fireballs) which may be capable of igniting the building or its contents, therefore threatening the occupants

- Exposure to flammable gas infiltration into the building, with subsequent build-up to a flammable concentration and ignition, causing occupant impact

- Exposure to toxic gas infiltration into the building, with subsequent build-up to a harmful concentration, causing occupant impact

Evaluation of building acceptability is to be made based on occupant vulnerability, which can be related to building exposure and/or building damage. The evaluation criteria for each of these hazards are to be developed by the owner/operator of the facility, with little guidance from API RP 752 and 753.

In the comprehensive building siting study, the impacts of each hazard are defined as:

- The threshold of fatality for building occupants

This definition has two purposes: first, the threshold of fatality is a discernible value for each hazard that is straightforward to define. In comparison to the specification of injury levels, threshold of fatality levels are often more narrowly defined. Second, if the building siting analysis progress to a QRA, a consistent set of endpoints is needed for all the hazards so that they can be combined in a coherent way. It is difficult to express an overall risk to building occupants if the hazards are defined by injury. For example, is a second degree burn injury equivalent to eardrum rupture from an explosion?

Based on the hazards applicable to the facility, buildings are evaluated for the characteristics that may influence occupant vulnerability. This involves an assessment of the construction, materials, and layout of the building, as well as its location relative to the facility's hazards. 


\section{BUILDING IMPACT EVALUATION}

As a building siting study progresses, certain buildings may be found to be vulnerable to one or more hazard impacts. If a building siting study reaches this state, there are several options within the comprehensive approach.

- Implement mitigation measures,

- Further detailed analysis specific to the hazards of concern,

- Evaluate the hazards semi-quantitatively, or

- Use a quantitative risk-based approach to demonstrate building acceptability.

Depending on the tools applied in the consequence analysis and the specific hazards of concern, there are multiple options available. The results of an initial consequence analysis can often be used to justify stopping the analysis, further detailed analysis, or to identify effective mitigation measures.

\section{Mitigation Measures}

Potential mitigation measures include three major categories: active, passive, and procedural. Active measures are dependent on human, electrical, or mechanical activation; thus, their reliability cannot be guaranteed. Passive measures require no input (decisions or activation) and are inherent to the process, equipment, building or layout. Procedural measures are written procedures performed by operators or another party. Some examples of mitigation measures that may be implemented due to a 752 study include: relocate personnel offices (passive), install gas detection and HVAC shutdown systems (active), or establishing escape and evacuation routes based on potential hazards (procedural).

Mitigation measures can change the analysis in one of two ways:

- Modification of the consequences to building occupants

- Modification of the probability of an undesired outcome(s)

Mitigation measures which change the consequence analysis can easily be quantified. However, modifications affecting probability can be difficult to properly quantify, so caution should be used when applying mitigation measures to modify event probabilities. Either type of modification, or a combination, is acceptable within the guidelines of API RP 752.

Mitigation measures can be reviewed and implemented at any time in the study, but implementation is more effective following a consequence analysis. This way a breakdown of the potential hazards can be utilized to determine the appropriate mitigation measures.

\section{Explosion Impacts}

If significant impacts to buildings are found to result from explosion events, a detailed blast analysis can provide a better description of the potential impacts. Explosion (or blast wave) analysis involves three steps: 
1. Blast impact calculation (overpressure, or overpressure and impulse)

2. Building damage level assessment (BDLA)

3. Occupant vulnerability assessment

Initial screening for vapor cloud explosion impacts is often accomplished by using lookup tables or blast curve models (i.e., using the QMEFS model [4], Baker-Strehlow-Tang (BST) model, or TNO multi-energy model), while further analysis could use more complex methods.

BDLA can be based on overpressure alone, involve the use of pressure-impulse (P-I) curves [5], or can adopt more advanced methods that take into account the actual structural response to a blast (structural analysis). Whatever the method, the end result is a definition of building damage, whether it is a percentage damage level or description of the type(s) of damage that may occur.

Building occupant vulnerability is often tied directly to the BDLA, but is sometimes expressed by an independent function (e.g., occupant fatality as a function of the percent building damage). Care must be taken that BDLA categories match the actual building construction, or are selected conservatively (i.e., they tend to over-predict building damage and therefore occupant vulnerability).

A final concern for overpressure impacts on occupied buildings is windows. The inclusion of windows in buildings can introduce potentially lethal hazards that occur at lower overpressures (or lower P-I levels) than lethal hazards from building structural failures. Because of this, the placement, design, and construction of windows must be considered in addition to the structural impacts.

\section{Radiation}

Fire radiation hazards have the potential to ignite occupied buildings. Buildings may be screened for vulnerability based on a thermal radiation flux. If further analysis is required, a building impact evaluation may be based on a transient exposure analysis, with consideration of the materials and type of construction for that building. The total fire radiation exposure (or dose) is a function of the fire's intensity and the duration of exposure.

Evacuation from a building may also be considered. It is possible that a building can be ignited due to fire exposure and the occupants can still safely evacuate. An evacuation analysis should consider occupants' exposure as they evacuate, due to the fire event that is impacting the building, accounting for decision delay times, escape path and speed, and any potential shielding.

As with overpressure, windows must also be considered. Windows can allow thermal radiation into a building, potentially igniting flammable materials in less time than ignition of the building exterior. 


\section{Infiltration}

All hazardous releases resulting in a hazardous gas exposure to a building, whether it is toxic or flammable, should be included as infiltration hazards. Buildings can be screened for gas infiltration by ensuring the impacts do not expose persons immediately outside the occupied building. A more detailed analysis may implement an infiltration model either at the start of the analysis or after the screening. Infiltration models calculate the building's exposure to an outside gas concentration that is necessary to create a hazardous environment inside the building [6], given the construction type and condition of the building to determine an infiltration rate. Special consideration should be taken when outside air intakes are present. When applying an infiltration model it is also important to consider the event duration and the vapor dispersion characteristics of multiple release hole sizes to capture the maximum impacts.

\section{Qualitative Risk Assessment}

If the consequence analysis shows that the occupants may be impacted and no feasible mitigation measures can be applied, then a qualitative risk-based argument regarding building impacts can be considered. The selection of a maximum credible event (MCE) defines something that is considered more likely to occur than the worst-case events. This is typically accomplished by defining a maximum release hole size to represent the MCE. Because smaller release hole sizes are generally more frequent than larger ones, the MCE magnitude is then expected to occur more frequently than worst-case scenarios. When a building is outside the MCE vulnerability zone, an acceptable level of risk (semi-quantitatively) is often assumed. However, if the MCE hazards also impact a building, there are further levels of probabilistic analysis that can be done. Besides the hole size definition of an MCE, consider that the MCE impacts are often a function of:

- Release orientation (initially assumed horizontal, with the wind),

- Worst-case weather conditions, and

- Wind direction, where any direction is possible.

In some building siting studies, the MCE impacts come from a small number of potential events. When this is the case, additional probabilistic evaluation can often show that the MCE with a horizontal orientation and worst-case weather conditions (including wind direction) represent only a small fraction of the range of potential outcomes. If so, this approach can be used to show that the risk to a building is believed to be sufficiently low, such that its location is acceptable.

\section{QUANTITATIVE RISK-BASED METHODS}

When there are multiple potential impacts to the buildings or options such as a detailed consequence analysis or semi-quantitative methods show that building impacts are still severe (unacceptable results), quantitative risk-based methods offer additional tools in a building siting analysis. The risk-based methods discussed here are fully quantitative approaches: they quantitatively describe the hazards (explosion impacts, fire vulnerability, etc.) of each event, as well as quantitatively defining the probability of each event, in order to develop measures of risk. Consequences are developed either in the same manner as the original analysis, or with detailed 
methods, and are typically developed for a wider range of potential events. Probabilities for each event are developed using tools such as failure frequency databases, ignition models, and probabilistic weather data. Several quantitative measures of risk are available:

- Overpressure exceedance curves (overpressure + probability)

- Probability of building damage curves (P-I + probability)

- Location-specific individual risk (consequence + probability for all hazards)

- F-N curve generation for building occupants (societal risk calculation)

Quantitative approaches for determining occupied building impacts follow the methodology of a QRA and should adhere to a recognized methodology for calculating risk [7]. A QRA can only represent total risk when it incorporates all potential hazards. Methods that focus on only one hazard are simply a measure of risk, since they do not fully describe the total risk to a building or its occupants.

\section{Overpressure Exceedance Curves}

The generation of overpressure exceedance curves (OECs) provides a substantial amount of information for specific locations that may be affected by explosion events. OECs represent a cumulative summary of the overpressure and probability of a full range of explosion events that could affect a building [8]. The OEC technique has been applied in facility or building siting studies worldwide [9], and is accepted as a viable means of making decisions concerning the suitability of buildings in and near flammable materials facilities, for compliance with API RP 752 and 753.

The application of overpressure exceedance curves represents a significant improvement over basing building siting solely on consequence analysis results. An OEC analysis brings probability into the analysis in a quantitative fashion, accounting for weather conditions, differing release sizes, and the specific layout of the facility. Once a probability threshold is selected, use of the OEC information can be applied much like in a consequence-only evaluation. If there are no significant infiltration or fire hazards for the building, this type of analysis can form the basis for building siting decisions. If OECs are used to site temporary or portable buildings (a "detailed analysis" according to API RP 753), care must be taken to evaluate the buildings with regard to their lighter construction, applying the proper occupant vulnerability criteria.

Example OECs are shown in Figure 1. 


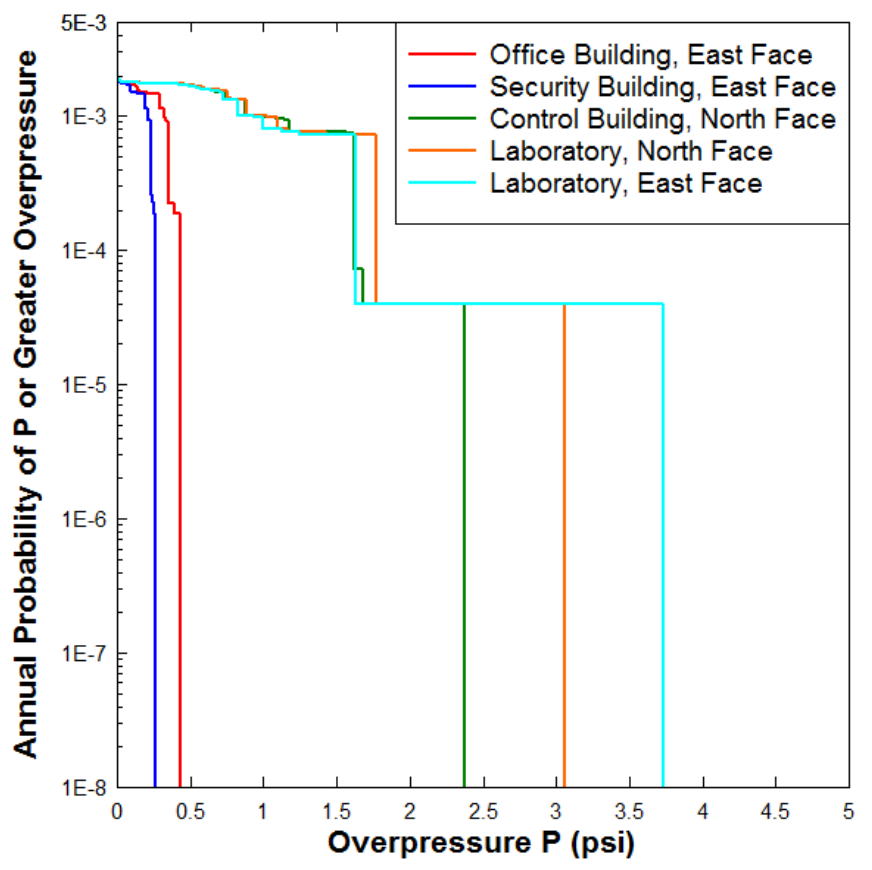

Figure 1 - Example Overpressure Exceedance Curves

OECs should be used when consequence-only calculations show unacceptable impacts to a building. They are often applied when detailed information about the building is not available, such that P-I information for the building does not exist or cannot reliably be generated. One caution: OECs should be used only when there is an occupant vulnerability relationship and accompanying risk-based criteria with which the results can be assessed.

\section{Probability of Building Damage Curves}

The use of probability of building damage (PBD) curves, like the OEC method, can make building siting studies more specific than other methods. This method uses both impulse and overpressure in the analysis to calculate building damage, thus presenting a more realistic assessment of the effects of accidental releases on occupied buildings [8]. Adopting a quantitative analysis methodology allows the analyst to account for varied conditions and parameters, as discussed above, and can provide a better estimate of the vapor cloud explosion risk to a building than simple consequence-only methods. It is important to note that the selection of P-I curves for use in this type of analysis should be based on the actual building being evaluated, or a set of curves that is sufficiently representative of the building in question. If uncertainties exist, the analysis should select curves for a weaker building (a conservative approach) consistent with the recommendations of API RP 752.

Example PBD curves are shown in Figure 2. 


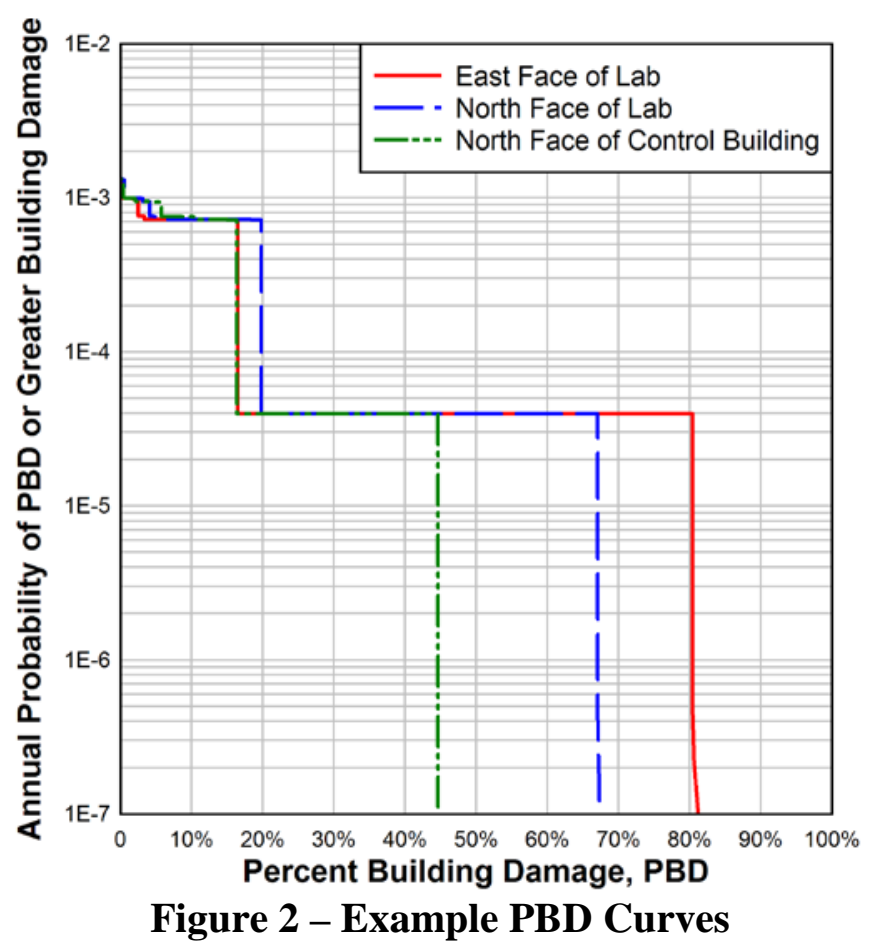

PBD curves may be used when consequence-only calculations show unacceptable impacts to a building and reliable P-I information for the building is available. PBD curves offer an advantage over OECs in that they incorporate the impulse information along with overpressure to determine building damage. As with OECs, PBD curves also require an occupant vulnerability relationship and risk-based criteria with which the results can be assessed.

\section{Individual Risk}

The generation of risk contours to represent the total risk to building occupants is applied in cases where multiple hazards are capable of impacting a building and mitigation measures are not feasible. Individual risk contours, typically defined as location specific individual risk (LSIR), are developed by following a QRA methodology, combining the consequences and probabilities of a wide range of accident scenarios, and evaluating the range of possible outcomes. When incorporating all hazards to building occupants, this methodology defines the frequency or probability that building occupants would be affected by the hazards present in the facility, and thus is a measure of the total risk to those occupants.

Figure 3 shows a set of total LSIR contours for building occupant hazards. In this example, risk was calculated for the threshold of building occupant fatality, and therefore the risk contours are only valid where buildings are, or may be, located. 


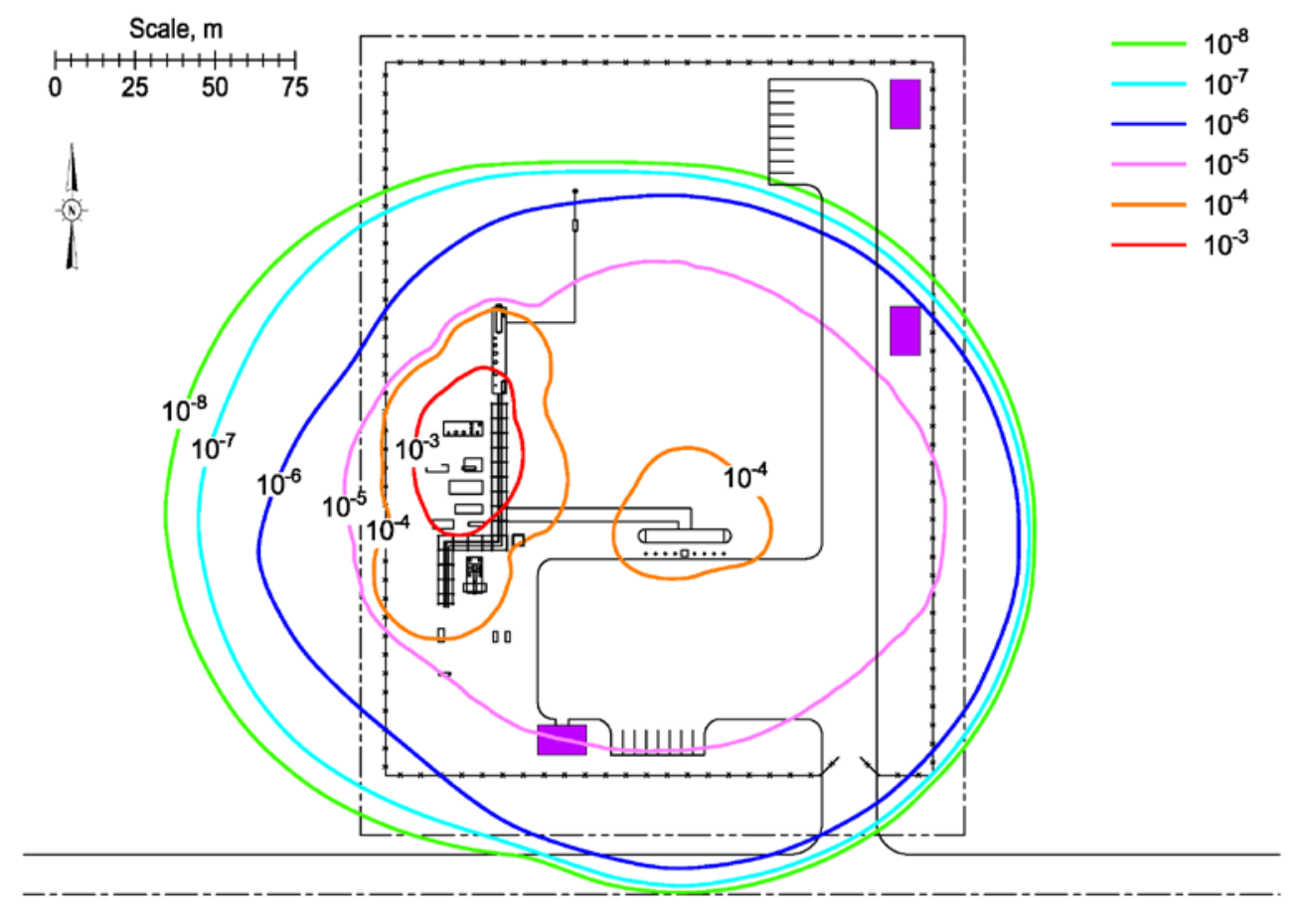

Figure 3 - Example Total Risk Contours for Building Occupants

The application of a QRA (with generation of LSIR) is useful when multiple hazards can impact a building, providing a complete risk-based evaluation for the building. LSIR is also useful when potential building locations are not defined and the proposed facility layout can be adapted to place occupied buildings in optimal locations.

When risk is presented as LSIR, the analyst can also incorporate occupancy into the building siting analysis. While building screening for consideration in the study cannot use occupancy, a QRA can. The risks to building occupants can then be modified by the amount of time people actually spend in the building, assuming that the hazards are possible at any time.

\section{F-N Curves for Building Occupants}

If all other risk-based methods show that the risk to occupants exceeds an individual risk criterion and no mitigation measures are available (including moving the building), the calculation of societal risk for occupants is a final option. Creation of an F-N curve [10] is a more advanced analysis, and like other risk-based methods, will require comparison to an acceptability criterion. Societal risk calculations, in this context, evaluate the potential number of fatalities within the building due to the potential external events. 


\section{BUILDING SITING STUDY METHODOLOGY}

The guidance and tools discussed thus far may be combined into a consistent and comprehensive methodology. The methodology developed is a staged process that allows the study to stop at multiple points when the analysis shows that occupants of the subject building(s) will be adequately protected. The methodology described below is summarized in the decision tree presented in Figure 4.

The first step of any building siting study serves to identify potential hazards and determine which buildings, if any, should be included in the analysis. This involves collection of information and a review of the process to determine the potential hazards that are inherent to the materials being handled. A decision concerning the inclusion of buildings is then based on criteria found in API RP 752 and 753. The guidance provided in API RP 752 and 753 regarding building inclusion can be summarized by the principle that all buildings intended for occupancy are to be included in the analysis.

The second step is a consequence analysis, which serves to evaluate the potential consequences of the hazards identified in the first step. The siting assessment can be stopped after the consequence analysis if it can be shown that adequate protection against either the worst-case or MCE scenarios is provided for building occupants through building spacing, building construction, process controls, or other engineering methods (mitigation). The MCE and/or worst-case scenarios can be considered a qualitative risk analysis; doing so combines consequence analysis and estimates of release frequencies to arrive at a qualitative measure of the risk posed to building occupants. This is normally achieved by assigning an MEC that qualitatively has a higher likelihood. For example, the worst-case analysis may evaluate pipe ruptures, while the MCEs may be limited to a maximum 2-inch diameter hole. 


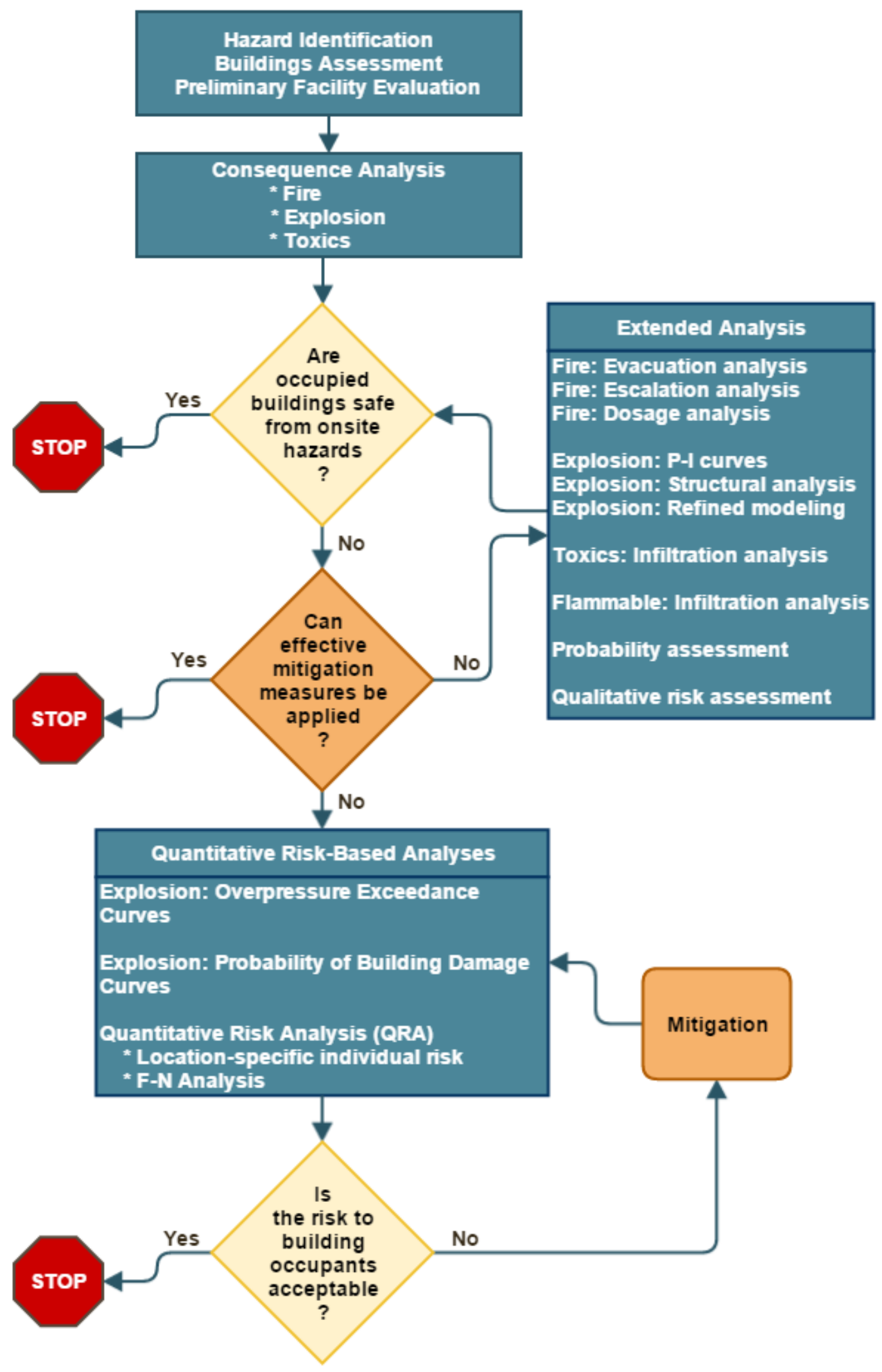

Figure 4 - Summary of Building Siting Methodology 
The overall intent of the consequence analysis is to determine if the risk to building occupants is either clearly acceptable or is below a given acceptability criterion; this criterion may or may not be quantitative at this point in the analysis. At any point after all hazards are evaluated, mitigation measures may be applied and evaluated. If the risk to building occupants is qualitatively found to be acceptable, the analysis can end.

An advanced step for a building siting analysis involves the application of quantitative risk-based evaluations, which often take the form of a QRA, a much more rigorous process than the initial assessment or consequence analysis steps. Quantitative methods first generate hazard footprints for a full range of release sizes, locations, and weather conditions. Next, the frequency of occurrence of each hazard footprint is determined using equipment failure frequencies, conditional probabilities, and site-specific weather data. All calculated hazard zones, with their respective probabilities and originating locations, are combined to produce measures of risk which demonstrate the frequency with which an event originating in the facility could adversely impact an occupied building and its occupants. The selection of the measures of risk that is to be applied is based on the type and nature of the hazards affecting the building occupants, and is informed by the consequence analysis portion of the study.

The impact to building occupants is determined by building damage levels or the selected hazard endpoints, which reflect the vulnerability of building occupants due to vapor cloud explosions, fires, toxic vapor clouds, and/or flammable vapor clouds. If the level of risk to building occupants is found to be acceptable, the analysis is complete. If not, mitigation measures that reduce event consequences or probabilities (or both) are implemented. The risk-based analysis can then be repeated, with modifications of the event consequences and/or probabilities based on mitigation measures to determine the risk, ending when the risk is found to be below a selected criterion.

\section{SUMMARY}

The methodology presented in this paper, summarized in the flowchart given in Figure 4, provides a comprehensive way to evaluate the potential impact to occupied buildings, in a manner consistent with API RP 752 and API RP 753. While this methodology does not specify any particular consequence models or hazard calculation techniques, the methods presented in this paper give the analyst an expansive set of tools for evaluating occupant vulnerability. In addition, the methodology given here can be applied to a wide range of facilities such that it can be adopted and applied by any company, group, or analyst.

\section{REFERENCES}

[1] API, Management of Hazards Associated with Location of Process Plant Buildings. API Recommended Practice 752, American Petroleum Institute, 1220 L Street, Northwest, Washington, D.C. 20005, 2009. 
[2] API, Management of Hazards Associated with Location of Process Plant Portable Buildings. API Recommended Practice 753, American Petroleum Institute, 1220 L Street, Northwest, Washington, D.C. 20005, First Edition, June 2007.

[3] OSHA, Code of Federal Regulations, Title 29, Part 1910.119 (29 CFR 1910.119). Process Safety Management of Highly Hazardous Chemicals, Occupational Safety and Health Administration, osha.gov.

[4] Melton, T. A. and J. D. Marx, "Estimating Flame Speeds for Use with the BST Blast Curves.” Process Safety Progress, Volume 28, No. 1, p. 5, March 2009.

[5] DOD, Approved Methods and algorithms for DOD Risk-Based Explosives Siting, Technical Paper No. 14, Revision 4, Department of Defense Explosives Safety Board, Alexandria, VA, 21 July 2009.

[6] Marx, J. D. and Ishii, B. R., "Infiltration Hazards for Building Siting Studies.” Process Safety Progress, in press, 2015.

[7] CCPS, Guidelines for Chemical Process Quantitative Risk Analysis. 2nd Edition, Center for Chemical Process Safety of the American Institute of Chemical Engineers, 2 Park Avenue, New York, New York, 2000.

[8] Marx, J.D., and K.M. Werts, "The Application of Pressure-Impulse Curves in a Blast Exceedance Analysis," Journal of Loss Prevention in the Process Industries, Volume 26, Issue 3, May 2013, Pages 478-482

[9] Chamberlin, G. A., and J. S. Puttock, Vapor Cloud Explosion Risk Management in Onshore Plant Using Explosion Exceedance Techniques, Hazards XIX: Process Safety and Environmental Protection, IChemE, 2006.

[10] Marx, J.D., and K.M. Werts (2012), "Application of F-N curves in API RP 752 building siting studies," Journal of Loss Prevention in the Process Industries, Volume 30, July 2014, Pages 301-306. 